\title{
A artificação da cultura: a economia da arte e o consumo da cultura no Musée du quai Branly
}

\section{Bruno Brulon}

- Universidade Federal do Estado do Rio de Janeiro / Rio de Janeiro, R], Brasil

$\checkmark$ brunobrulon@gmail.com

\section{RESUMO}

O artigo resulta da investigação da cadeia museológica que leva à consagração das "artes primeiras" no Musée du quai Branly. Concebido para neutralizar o valor cultural dos objetos nos seus contextos precedentes à entrada para o mercado europeu, o quai Branly, como um museu de arte, vem se voltando quase que exclusivamente para o mercado de arte e para os colecionadores ao constituir a sua coleção. Tal neutralidade cultural, que se dá pelo processo de silenciamento histórico, é construída por uma museologia da artificação na qual os objetos são elevados ao estatuto de "obras de arte" no processo circular que vai do museu ao mercado e vice-versa. Nas "artes primeiras", a "obra" é o produto de uma tradução cultural por meio da qual elementos de outras culturas são interpretados como arte para poderem transitar como mercadorias no contexto internacional. 


\section{INTRODUÇÃO}

Ao longo de sua existência, nos últimos dez anos, o Musée du quai Branly apresentou ao público europeu o espetáculo das "artes primeiras" por meio da encenação de um distanciamento imaginário dos contextos dos quais os objetos em suas coleções tiveram origem e dos seus produtores primários. Traçando linhas, limites e fronteiras simbólicas entre o observador e a "coisa" mostrada, o museu posiciona as suas "obras de arte", concebidas assim no Ocidente contemporâneo', em vitrines distanciadas do olhar do observador, de modo que as "artes primeiras" ali encenadas pressupõem claras demarcações entre o contexto histórico-cultural em que foram produzidas e o contexto ocidental em que são, atualmente, consumidas como mercadoria e/ou como objetos de museu.

Entendendo, na presente análise, os objetos de museus como um tipo particular de dádiva , que, segundo Maurice Codelier (2007: 82), "os deuses ou espíritos teriam realizado aos ancestrais dos homens, e que seus descendentes, os homens atuais, deviam guardar preciosamente", estes, também pensados em certos contextos como bens inalienáveis, são comumente apontados como opostos às mercadorias. Tal oposição, que pretendemos desconstruir na presente análise, entre a dádiva e a mercadoria se baseia no fato de que enquanto a dádiva estabelece um laço entre as pessoas e as coisas e incorpora o fluxo das coisas ao fluxo das relações sociais, a mercadoria representaria a troca livre-moral e culturalmente - de bens por outros bens, troca que seria mediada pelo dinheiro e não pela socialidade (Appadurai, 2007: 11).

O contraste entre uma teoria da reciprocidade e o mercado de trocas é legítimo; ele está presente não apenas no discurso antropológico como em alguns níveis da realidade social, sendo um deles o museu. Por outro lado, os museus ajudam a demonstrar que os valores são construídos socialmente-pelas interações sociais e culturais e pelo próprio processo da musealização-e que eles mesmos incorporam valor material aos objetos que coletam e expõem. Como explica Appadurai, nas trocas, os objetos não são difíceis de adquirir por serem valiosos, mas são valiosos na medida em que resistem ao nosso desejo de possuí-los (Simmel, 1978: 67 apud Appadurai, 2007: 3). Com o discurso da inalienabilidade, os museus fazem da coisa musealizada objeto inalcançável do desejo. Não há sacrifício capaz de torná-lo trocável, uma vez que ele deixa de ser pensado como mercadoria. O paradoxo, logo, é o de que se, por um lado, ao entrar no museu o objeto torna latente o seu valor de uso, por outro, ainda que indiretamente, não perde de vista o seu valor de troca. Sempre haverá estimativas², na possibilidade de um dia o objeto retornar ao mundo "profano", ao ser alienado pela instituição que o detém em nome da sociedade, e assim voltando a circular na esfera mercantil que existe para além da musealização.
1 Por "Ocidente", entendemos não o recorte geográfico estritamente, mas o recorte simbólico de produção de cultura que tem como centro a cultura produzida por alguns países do hemisfério Norte e que é reproduzida, por meio de regimes de poder específicos, no restante do mundo dito global.

2 O valor econômico do objeto nunca se perde de vista, seja como uma cifra estabelecida pela seguradora responsável por ressarcir o museu do investimento na peça em caso de perdas, ou mesmo como um traço do histórico do objeto que também servirá para lhe agregar valor (ex.: por quanto foi comprada a peça no último leilão em que fora arrematada) 
Entre a dádiva e a mercadoria, os museus, através dos anos de sua existência, foram levados a lidar com as múltiplas variações de estados que uma coisa pode incorporar. A partir da introdução de uma perspectiva sobre a circulação de objetos por redes de socialidades distintas, o dualismo tradicionalmente aceito entre o seu "valor de troca" e o "valor de uso" - presente em Marx-é suplantado por um interesse pelos diferentes regimes de valor que fazem os objetos, o que leva o pesquisador, a partir da perspectiva de Appadurai (2007: 4), a despertar o interesse pela movimentação das coisas através dos diversos regimes de valor no tempo e no espaço. Tal deslocamento ou percurso observado nas coisas que adquirem valor pode fornecer pistas sobre o seu contexto social e humano. Como instituições que produzem e legitimam a arte e a cultura que circulam no mundo contemporâneo, os museus são importantes agentes da ordem social que abarcam tanto um regime de valores simbólicos quanto um regime de valores mercantis, por vezes percebidos como indissociáveis.

O presente texto é resultante da investigação da cadeia museológica ${ }^{3}$ que leva coleções de objetos etnográficos e objetos de arte a se consagrarem como "artes primeiras" no celebrado Musée du quai Branly, localizado na cidade de Paris. A pesquisa etnográfica a que ele se refere se deu ao longo dos anos 2011 e 2012, em contato constante com o museu e seus conservadores, contando ainda com o acompanhamento da compra e venda de obras por este museu em leilões de arte primitiva ou diretamente com colecionadores.

Percebendo o museu como um agente central em um "mundo da arte" (Becker, 2010) criado para as "artes primeiras", é possível inferir que a análise etnográfica das aquisições realizadas por seus conservadores nos últimos anos demonstra a predominância de convenções impostas por um mercado das "artes primeiras" em ascensão. Concebido estrategicamente para neutralizar o valor cultural dos objetos nos seus contextos precedentes à entrada para o mercado europeu, o quai Branly, como um museu europeu de arte, vem se voltando quase que exclusivamente para o mercado de arte e para os colecionadores ao constituir a sua coleção atual ${ }^{4}$.

Tal neutralidade cultural ${ }^{5}$, que se dá pelo processo correlato de silenciamento histórico ${ }^{6}$ é construída por uma museologia da artificação (Heinich e Shapiro, 2012) na qual os objetos são elevados ao estatuto de "obras de arte" num processo circular que vai do museu ao mercado e vice-versa. Sendo assim, por meio da troca mercantil de certos vestígios de culturas não europeias um patrimônio europeu de obras de arte é fundado e um novo mercado, que aqui identificaremos como o mercado das "artes primeiras" ou primitivas, é simultaneamente criado para alimentar alguns museus e colecionadores que colecionam indistintamente a cultura como se fosse arte ou a arte como se fosse cultura.
3 Podemos considerar que a cadeia museológica tem início no campo, onde os objetos são coletados, abarcando todos os processos que se seguem de identificação, classificação, higienização, acondicionamento, seleção, exposição, e até sua extensão sobre os públicos, os colecionadores privados, o mercado e os diversos outros agentes indiretamente ligados a ela.

4 Segundo os números divulgados pela instituição, no ano de 2011, em que esta pesquisa estava sendo realizada, foram arrecadados pelo Serviço de Mecenato do museu a soma de 1.679.781 euros, montante que é direcionado prioritariamente para a compra de novos objetos. Ao longo do mesmo ano, o quai Branly adquiriu 745 novos objetos. Entre as compras e doações para o museu no ano, foram somados um valor total de 2.300 milhões de euros (quai Branly, RA, 2011:16)

5 Sobre esse processo de neutralização cultural pelas coleções do quai Branly, ver Ciarcia (2001).

6 Apesar de sucessivas tentativas, algumas mais recentes, de incluir a participação de indígenas nos processos de elaboração de exposições de curta duração, tais "parcerias" se mostraram por vezes problemáticas na medida em que o museu priorizava o discurso estético em detrimento dos elementos históricos e culturais das populações tratadas, como se observa no texto de Brulon (2013). Nos primeiros dez anos de existência do museu, tais parcerias se mostraram apenas no nível da elaboração de exposições, sendo a gestão das coleções do museu atribuição exclusiva dos conservadores que, no caso do quai Branly, são europeus. 


\section{A MUSEALIZAÇÃO PELA ARTIFICAÇÃO: O MUSEU COMO PRODUTOR DE CHEFS-D'đEUVRE}

O que faz um objeto etnográfico ${ }^{7}$ se tornar uma obra de arte? Essa é a pergunta que muitos dos críticos ao projeto do Musée du quai Branly ainda se colocam. Para que uma tal revolução de valores fosse realizada pelos idealizadores do museu, um complexo processo de acirradas disputas ocupou o centro do campo museal francês nos anos 1990, quando se dava a passagem do tempo da hegemonia do modelo científico representado pelo Musée de l'Homme 8 para o surgimento do Musée du quai Branly, e enquanto se organizava um mundo da arte à parte para as "artes primeiras". Após mais de duas décadas de debates e questionamentos, esses objetos já são amplamente reconhecidos como arte em sua nova vida museal que legitima a sua presença como chefs-d'œuvre $e^{9}$ no contexto europeu.

A constituição de coleções é reconhecidamente um modo de definição das identidades culturais, mais ou menos recentemente percebidas como processuais e negociadas. No chamado Ocidente, como lembra Clifford (1994: 71), o ato de colecionar tem sido há muito uma estratégia de "distribuição de um eu" ou de uma cultura e uma autenticidade possessivos que se constituem, evidentemente, a partir de processos de trocas com outras culturas também em busca de alguma definição. Consequentemente, constituir coleção nunca é um processo inocente ou natural, estando o ato invariavelmente marcado por relações de poder variantes. Sendo assim, para além de se ver o quai Branly como um instrumento unidirecional do poder de uma antiga metrópole sobre suas colônias, entendemos essa instituição como um ponto nodal de relações de poder e interesses múltiplos, resultante, portanto, da própria dinâmica das identidades como esta é percebida no mundo contemporâneo.

A história da descontextualização de objetos coletados, em sua maioria, em função da colonização, pode ser contada sob o ponto de vista de um certo colecionador. Trata-se daquele que foi o porta-voz do movimento cujo início no mundo das artes data do período seguinte ao movimento surrealista, nos anos 1930. Em meio à crise dos museus etnográficos na França, e diante da incerteza sobre o destino das suas coleções, Jacques Kerchache ${ }^{10}$ (1942-2001) coloca em questão o tipo de tratamento museológico que elas recebiam nessas instituições. Nesse momento, a questão sobre o destino das "artes primeiras" já tomava os corações e as mentes de pensadores de todo o mundo. Em janeiro de 1990, Alpha Oumar Konaré11 (1946-), então presidente do Conselho Internacional de Museus (ICOM), dirige-se ao primeiro-ministro francês, Michel Rocard, ressaltando a ausência de valorização das artes africanas na França, e sugerindo a criação de um novo estabelecimento, o que deveria conduzir "à valorização, ao fortalecimento e à renovação de outros museus especializados sobre a África" (Konaré, 1990 apud Grognet, 2009). Alguns meses mais tarde, Kerchache se tor-
7 Na época em que escreveu o seu "Manuel d'ethnographie", Marcel Mauss afirma que a etnografia comparada só terá algum efeito de valor se ela "se fundar sobre comparações de fatos e não de culturas" (Mauss, 2002: 21). A principal fonte para estas comparações era o objeto etnográfico coletado pelos etnógrafos no campo, de acordo com os critérios prescritos por pensadores como o próprio Mauss, ou Marcel Griaule.

8 Criado por Paul Rivet e Georges Henri Rivière, em 1937, o Musée de l'Homme, herdeiro do Musée d'Ethnographie du Trocadéro, ao longo da maior parte do século XX, na França, representou um modelo bem sucedido de instituição científica que corresponde a uma definição dupla: ele é um museu consagrado à espécie humana em seu conjunto, e um museu consagrado às civilizações não europeias (ou classificadas pelos europeus na categoria imprecisa de "não ocidentais"), assim como ao folclore europeu (L'Estoile, 2007: 190).

9 Obras-primas em português.

10 Galerista e amante das artes primitivas, Kerchache realizou numerosas viagens de estudos entre os anos de 1958 e 1980, na África, na Ásia, nas Américas e na Oceania. A partir de 1960 ele abre uma galeria de Belas Artes em Paris, na qual viria a expor desde arte contemporânea às artes primitivas. A partir dos anos 1970, ele participou de diversas exposições importantes no mundo, como curador e consultor

11 Presidente do ICOM de 1989 a 1992, ele se tornaria o primeiro presidente democraticamente eleito do Mali, entre 1992 e 2002 
naria conhecido ao publicar no periódico "Libération" o seu "Manifesto pelas chefs d'œuvre do mundo inteiro nascerem livres e iguais"12. Enquanto isso, uma transformação já vinha se dando em instituições privadas, como o Musée Dapper ${ }^{13}$, que valorizavam as "artes primeiras" mostrando as suas chefs-d'œuvre. Não demoraria para que essa nova tendência alcançasse as grandes instituições nacionais.

O Musée des Arts d'Afrique et d'Océanie, criado em 1962, por André Malraux, e rebatizado em 1990 como Musée national des Arts d'Afrique et d'Océanie teria a sua originalidade ressaltada no que se refere às suas aquisições. Através de um comitê técnico preocupado com o mercado de arte formado após a Segunda Guerra, as obras eram escolhidas, antes de qualquer outro critério, "pela sua significação plástica, sua contribuição no domínio das formas" (Meauzé, 1973:13 apud Viatte, 2002: 13) e, logo, pelo seu valor como obras de arte. Esse museu nacional foi representativo de um reconhecimento pelo mundo dos museus dessas artes "periféricas", que tinham sido até então rejeitadas pelo palácio do Louvre, ainda que já fizessem parte de um "sistema de arte e cultura" (Clifford, 1994) desde a sua entrada para o Musée d'Ethnographie du Trocadéro ${ }^{14}$. É, entretanto, a partir desse primeiro momento de reconhecimento nacional que se abrem os caminhos para a criação de um "museu das artes primitivas".

A partir do contato e influência de Kerchache, em 1995, o presidente Jacques Chirac (1932-), ele próprio um conhecedor das "artes primeiras", se empenha em convencer diversas lideranças em museus franceses da "bem fundada revolução" (Pierrard, 1996: 85 apud Grognet, 2009: 453). Rapidamente a questão se volta para o emblemático Musée de l'Homme e para os seus quase 300 mil objetos etnográficos que, segundo a proposta de criação de um novo museu, iriam se metamorfosear em peças ditas de "artes primeiras" por meio de uma decisão governamental (Grognet, 2009: 452). Uma comissão's é criada em 14 de novembro de 1995, por iniciativa do presidente. Em setembro de 1996, tal comissão, liderada por Kerchache, iria propor a criação de uma nova instituição autônoma colocada sob a tutela dupla do Ministério da Cultura e do Ministério de Pesquisa e Educação Nacional. Além disso, decidiu-se que o período temático que o futuro estabelecimento cobriria não seria limitado, de modo que fosse mostrada aos visitantes uma visão completa das formas das "artes primeiras" incluindo as obras de arte contemporânea. Começava a se desenhar a instituição que ganharia o nome abstrato de Musée du quai Branly ${ }^{16}$.

Como aponta Dias (2007: 66), longe de se formar por um processo de filiação, o museu das "artes primeiras" emergiu por meio de um processo de fusão, de inclusão e de exclusão de diversos outros museus e, como consequência, de diversas tradições de pesquisa. O resultado foi uma museologia pautada no conceito inclusivo e impreciso de "artes primeiras", noção esta que passou a ser disseminada mais amplamente - ainda que fosse, ao mesmo tempo, duramente
12 Manifeste pour que les chefs d'œuvre du monde entier naissent libres et égaux (no original).

13 OMusée Dapper, em Paris, foi criado em 1986 como uma instituição privada, expondo arte primitiva desde então.

14 O primeiro museu etnográfico a ocupar o espaço do antigo Palais du Trocadéro, o Musée d'Ethnographie du Trocadéro foi criado em 1878, por seu fundador, Ernest-Théodore Hamy, etnólogo americanista. A partir de 1928, após um período de crises que levou ao processo de degradação de suas coleções, o museu passa a ser dirigido por Paul Rivet que, ao lado de Ceorges Henri Rivière, seria encarregado da modernização da museografia etnográfica. Em 1937, o Musée d'Etnographie deixa de existir dando origem ao Musée de l'Homme no mesmo local.

15 A comissão seria composta por doze membros, correspondendo a uma complementaridade de competências entre conservadores de museus e cientistas de universidades e instituições administrativas, que teriam por missão refletir sobre a valorização das "artes primeiras" na França. Nomeado como presidente de honra, Claude Lévi-Strauss conferia um aval antropológico às discussões.

16 Inicialmente o museu foi intitulado de "museu de artes primitivas", o que gerou grande discussão entre os etnólogos que viam uma forte conotação etnocêntrica por trás do termo. A instituição teve, então, seu nome alterado para o de "museu de artes primeiras", como museu dedicado àquelas artes 
criticada. O termo carrega em si a missão de fazer com que os povos antigamente dominados se tornem sujeitos criadores, sob os olhos do Ocidente, de modo que a condescendência, a depreciação ou a obsessão fossem transformadas em admiração pelos tesouros dos quais eles foram os detentores (Ciarcia, 2001). Essa museologia, que pretende "libertar" as culturas dos "outros" das amarras de um passado que, ao ser ignorado, liberta simbolicamente tanto os dominados quanto os dominadores de sua culpa e responsabilidade, permite que a "cultura" dos povos colonizados seja apropriada sem que se leve em conta as implicações políticas dessa apropriação uma vez que ela se dá mediada pelo mercado e não mais pela etnologia.

\section{AQUISIÇÃO E ARTIFICAÇÃO: DO MUSEU-LABORATÓRIO AO MUSEU-BALCÃO}

Nos museus de arte, a absorção das criações de povos que foram, por muito tempo, renegados pela história da arte, significou um estreitamento dos meios de acesso de objetos em geral. Isso porque "para absorver todas as culturas, foi necessário que elas passassem por um filtro" (Desvallées, 2007: 50). Como resultado, só se conserva o que pode ser considerado "belo", segundo critérios variáveis e que buscam se justificar, no discurso dos conservadores do museu, como mais ou menos impessoais. A adoção dos critérios de beleza - pelo mercado, primeiramente, e depois pelos museus - pode ser vista como um sintoma da incapacidade do Ocidente de julgar esses objetos por seu valor histórico, uma vez que o valor etnográfico já se encontrava em crise ${ }^{17}$.

A observação dos processos de musealização colocados em prática no âmbito de um projeto de amplificação das doações e aquisições iniciado, mais expressivamente, a partir dos anos de 2006 e 2007 deflagra o processo de artificação das culturas não europeias pelo quai Branly. A reconfiguração de sua coleção, principalmente pela incorporação da arte contemporânea como forma de expressão dos "povos primeiros", pretende marcar a identidade do quai Branly entre os museus do século XXI e sua ligação estreita com o mercado.

A criação do museu, logo, representou para o cenário dos museus franceses a predominância da linguagem das chefs-d'œuvre, na qual a exposição de objetos tratados como arte está fundada sobre a singularidade de cada peça. Uma vez que se chega à conclusão antropológica de que um conjunto de objetos não pode fazer alusão a "uma cultura", consequentemente, estes passam a ser contemplados isoladamente pela cultura europeia, e aquilo que guardam de valor tem ligação primordial com suas características intrínsecas. A fluidez pretendida para o espaço expositivo é uma das incongruências mais aparentes dessa abordagem. Considerando o percurso construído com base na presença singular de cada uma das chefs-d'œuvre, rompe-se com a possibilidade de qualquer narrativa consideradas "primordiais", o que não pareceu resolver satisfatoriamente o problema. Tendo os debates acerca do nome do projeto se alongado até às vésperas da inauguração do museu (algumas placas nas ruas de Paris até hoje indicam o nome antigo), este passa a se chamar, simplesmente, pelo nome do local onde estaria localizado, o quai Branly, evidenciando-se, assim, o seu caráter nacional e ocidental. Em 2016, ao completar dez anos, o museu ganha o subtítulo de Musée du quai Branly-Jacques Chirac, em homenagem ao ex-presidente e seu idealizador.

17 Sobre a crise do modelo de museu etnográfico tradicional, que se baseava principalmente em critérios etnográficos para constituir suas coleções, ver a tese de doutorado de Fabrice Grognet, orientada por Jean Jamin, sobre a passagem da coleção etnográfica do Musée del'Homme para o Musée du quai Branly (Grognet, 2009). 
- histórica, antropológica ou mesmo artística (no sentido de uma continuidade estilística). Hoje, o que sustenta a coerência dos enunciados e das aquisições do Musée du quai Branlyé a ideia, quase mitológica, de que as "artes primeiras" permitem conciliar exigências contraditórias (L'Estoile, 2007: 251).

Como um museu que conseguiu se posicionar na zona imprecisa entre áreas diversas do conhecimento, o quai Branly buscou se diferenciar do perfil do museu-laboratório colocado em prática no Musée de l'Homme. No novo modelo de museu que se criou, as interlocuções são múltiplas e, em sua maioria, externas ao corpo de profissionais permanentes da instituição. Com isso, o museu se torna um espaço consagrado por diversas articulações que legitimam a sua ação em diferentes campos, e forjam a sua autoridade. Atuando, para todos os efeitos, em um museu de arte, os conservadores do quai Branly não hesitam em admitir que os seus interlocutores principais são os colecionadores privados, $\mathrm{e}$ não os pesquisadores e os especialistas (Delpuech, 2011).

Mas como se escolhe uma chef-d'œuvre para ser introduzida à coleção do quai Branly? Quem tem a autoridade para elegê-la nesse novo estabelecimento que não é composto por pesquisadores e especialistas como os do passado? ${ }^{38}$ Desde o início do projeto se definiu, por decisão de Chirac e Kerchache, que o quai Branly seria um museu sem pesquisadores permanentes (Taylor, 2012). Os etnólogos poderiam se envolver, mas eles não atuariam como etnólogos a não ser por meio de bolsas de pesquisa temporárias que não fariam deles pesquisadores da instituição' ${ }^{19}$.

Como descreve André Delpuech (2011), chefe da unidade patrimonial das coleções das Américas no museu, por meio dos programas de bolsas, ou consultas sobre os objetos e os documentos, ou, ainda, nas participações nos catálogos das exposições e em programas de pesquisa no museu, estabelecem-se relações com a comunidade científica nacional e internacional. No entanto, a ordem se inverte em relação à lógica estabelecida nos museus etnográficos precedentes, pois agora é o museu que recorre aos cientistas e não mais os cientistas que têm o museu como seu laboratório ao qual podem recorrer a todo momento. Sendo assim, para além de mudar relações institucionais, o Musée du quai Branly altera uma certa hierarquia de saberes e de poderes estabelecida, instaurando - por meio de suas aquisições atuais - a lógica do balcão.

Como confirma Delpuech, é possível notar que, se o Musée d'Ethnographie e o Musée de l'Homme tinham como interlocutores primordiais os exploradores e os etnólogos, o Musée du quai Branly dialoga, principalmente, com os colecionadores e marchands. Delpuech explica, ainda, que, enquanto o Musée de l'Homme não possuía conservadores e era formado exclusivamente por pesquisadores e professores do CNRS, que trabalhavam juntos na gestão das
18 Anteriormente, o Musée de l'Homme fora idealizado pelo americanista Paul Rivet e seu assistente Ceorges Henri Rivière para servir aos interesses de pesquisa de algumas gerações de etnólogos, incluindo desde Marcel Mauss e Lucien LéviBruhl a Claude Lévi-Strauss. $O$ quai Branly, por sua vez, abre-se a novos interesses de pesquisa que podem incluir a estética, as artes plásticas e a filosofia.

19 Apesar dos diálogos disciplinares serem múltiplos, sobretudo nos processos de elaboração das exposições de curta duração do museu, aqueles profissionais que atuam diretamente na gestão das coleções do quai Branly não são etnólogos. Como justifica Stéphane Martin, a pesquisa antropológica "já havia desertado o Musée de l'Homme, passando a ser feita em centros acadêmicos como a École des Hautes Études en Sciences Sociales-EHESS, o Collège de France ou no Centre National de la Recherche ScientifiqueCNRS" (Martin, 2007: 21). 
coleções, no quai Branly os conservadores são os únicos gestores do acervo ${ }^{20}$. Conservadores e colecionadores, em razão do interesse comum pelos objetos e coleções, vêm sendo cada vez mais associados na museologia francesa, e passam a estabelecer relações estreitas, não apenas no quai Branly, como também nos principais museus de arte. Essa questão coloca problemas objetivos, especialmente para os antropólogos. Como um museu herdeiro das importantes instituições etnográficas do passado pode atualizar as suas coleções no presente se apropriando de critérios inicialmente traçados pelo mercado de arte?

Segundo Nathalie Heinich e Roberta Shapiro (2012), a museologia como disciplina que pressupõe uma prática específica pode ser observada em certos contextos como um dos vetores da artificação. No sentido da prática exercida no Musée du quai Branly, comandada por conservadores cuja proximidade com o mundo dos colecionadores e marchands é flagrante, a museologia é, em si, responsável pela artificação. A emergência da figura do "autor" das exposições na função do conservador (no caso das exposições de longa duração do museu) e do "commissariat d'expositions" ${ }^{21}$ (no caso das exposições de curta duração) tende a fazer, daquela que foi por muito tempo uma função interdisciplinar e interna dos profissionais de museus, um exercício de competências quase artístico (Heinich e Shapiro, 2012: 279).

Em parte, a marcante diferença dos critérios utilizados nas novas aquisições do quai Branly se justifica no fato desse museu não priorizar mais a coleta no campo (Delpuech, 2011). Como afirma a etnóloga Anne-Christine Taylor, que, entre os anos de 2005 e 2013 esteve na direção do Departamento de Pesquisa e Educação do museu, poucos são os objetos adquiridos in situ pelo Musée du quai Branly atualmente. Raramente, são realizadas expedições de coleta no sentido tradicional do termo, mas estas são de período curto, e, na maioria das vezes, os conservadores (que são quem as realizam, e não os etnólogos) já têm em mente aquilo que buscam no campo. O que se vê com mais frequência no museu é um novo tipo de "expedição artística", em que o conservador vai ao campo encontrar colecionadores e marchands, que, em alguns casos, são os responsáveis por fazer a mediação com os produtores.

Segundo Stéphane Martin (2007: 21), atual presidente do quai Branly, para enriquecer as coleções do museu "é irrealista depender da coleta". A redução do trabalho de campo, e o fim de uma relação estreita da etnologia com os museus, resul tou na crescente autoridade dos colecionadores. Essa nova autoridade museológica, que, de certa forma, guia as decisões dos conservadores e engendra o seu "amor" pela arte que devem colocar nas vitrines da exposição, representa uma revolução no controle desses objetos no contexto dos museus. Considerado um dos mais importantes "museus etnográficos" do mundo contemporâneo, o quai Branly é, ipso facto, um museu de arte.
20 A formação dos conservadores na França, sobretudo entre aqueles profissionais formados no Institut National du Patrimoine (INP), vem sendo cada vez mais embasada no campo das artes, tendo este instituto descendido do antigo Institut Français de Festauration des Oeuvres d'Art (IFROA), e estando ele hoje ligado ao Institut National d'Histoire de l'Art (INHA). Os conservadores atuam como gestores de coleções, trabalhando com temas pouco especializados.

21 O comissariado de exposições, função similar à do curador, é ocupado geralmente por personalidades convidadas competentes em determinados temas expositivos no Musée du quai Branly. Nessa função, além de grandes nomes do campo das artes, alguns renomados intelectuais já desempenharam o papel de idealizar exposições de curta duração, entre os quais podemos citar o etnólogo Bruno Latour e o historiador Serge Gruzinski, que trabalharam em parceria com os conservadores permanentes da instituição. 
A mudança axiológica provocada no mundo dos museus pelo modelo do quai Branly trata da instauração de um novo regime do gosto - que não é criado pelo museu, já existindo antes dele como veremos adiante-, norteado pelo mercado e pelas escolhas individuais dos colecionadores privados. Neste sentido, os processos de artificação da cultura promovidos pelo museu permitem que objetos produzidos com valores culturais específicos dentro de certos grupos sejam trocados como mercadorias entre diferentes agentes e instituições no contexto europeu. Inventa-se, assim, um novo tipo de museu de arte com coleções etnográficas.

\section{UM “MERCADO DE ARTE" PARA AS “ARTES PRIMEIRAS"}

Segundo Raymonde Moulin (2003: 45), "a arte é um bem raro, durável, que oferece ao seu detentor serviços estéticos (prazer estético), sociais (distinção, prestígio) e financeiros". Uma chef-d'œuvre é um bem que pode ser possuído tanto por proprietários individuais quando por coletividades (através dos museus). 0 seu preço - que está ligado à sua singularidade e, portanto, o seu valor primeiro provém de sua raridade -é estabelecido por um conjunto de valores que lhe são exteriores. Como aponta Moulin (2003: 15) sobre as obras de arte, as variáveis relativas à demanda devem ser levadas em consideração. O caso ideal típico da limitação quase absoluta da oferta faz com que se imponha uma situação de monopólio gerada pela unicidade da obra. Se, como constatou Simmel (1978: 67 apud Appadurai, 2007: 3), desejamos os objetos na medida em que eles resistem ao nosso desejo, logo, os objetos que possuem valor no mundo das artes são permeados pela aura da resistência, e é essa resistência à posse e ao desejo profano que configura a fonte do valor que os objetos adquirem ao entrarem em um museu.

Museus são reconhecidos como espaços de permanência, e, a noção de permanência tem o seu sentido primeiro na crença amplamente disseminada na perenidade das coleções museológicas. Particularmente na França, onde objetos, em geral, não podem ser alienados pelos museus - o que quer dizer que aquilo que entra para a cadeia museológica não poderá ser retirado dela exceto por meio de leis específicas e conjunturais - estes são vistos, então, como proprietários solenes daquilo que não pode pertencer a nenhum indivíduo particular.

Para além do desejo dos colecionadores de possuir objetos de arte como bens pessoais, deve-se reconhecer que o poder peculiar desses objetos não está, primordialmente, ligado ao seu valor como itens de troca. O poder dos objetos de arte em museus reside nos processos simbólicos que eles provocam nos observadores, e estes têm características sui generis que são parcialmente indepen- 
dentes dos objetos em si mesmos. Pertencendo a uma esfera de trocas da qual as pessoas comuns se veem excluídas, os objetos musealizados não deixam de ser "objetos de desejo" - um desejo de possuí-los, ainda que não materialmente. No mercado, o preço depende da competição final entre os agentes (estes marcados por uma rede de influências que envolve os museus), considerando o seu desejo de possuir a obra (ou um dado tipo de obra), e os seus poderes de compra. Neste sentido, o preço é, enquanto tal, amplamente imprevisível, não somente nos leilões mas também nos intensos processos de negociação direta com os colecionadores. Nos últimos anos se viu uma ascensão progressiva do mercado das "artes primeiras", que pode ser observada a partir da constatação de uma alta marcante dos preços das obras vendidas em diversos contextos.

Em 1897, na ocasião da sangrenta expedição britânica punitiva ao reino do Benin, que resultou no saque do palácio do Obá, aproximadamente mil placas de bronze, datando de vários séculos antes, foram arrancadas do palácio e dispersas em Londres pelo Foreign Office. Muitas delas alimentaram as coleções de grandes museus europeus, onde ainda permanecem atualmente, como no caso do British Museum. Outras foram comercializadas por marchands, alcançando o preço de algumas centenas de libras esterlinas por peça. Hoje, como assegura Patrick Caput, consultor da Sotheby's ${ }^{22}$, essas placas “valem correntemente a bagatela de várias centenas de milhares de euros" (Wavrin, 2006: 61). Em dezembro de 2004, em Paris, uma delas, datando do final do século XVI ou início do XVII, foi vendida pelo preço de 691.200 euros, tendo essa mesma peça sido avaliada em 3 mil libras em 1961. Essa venda representou um dos recordes de preço pago por peças de arte africana, que já foi batido por cifras muito mais elevadas atualmente.

A ascensão das "artes primeiras" em um mercado de arte próprio foi sustentada por uma nova lógica de mercado que está baseada na conjugação de tendências aparentemente contraditórias: a perenidade da arte primitiva fundada em seu desligamento da história, por um lado, e o "turbilhão inovador perpétuo" que marca a produção artística das últimas décadas, por outro. Para Moulin (1992: 49), esse "turbilhão inovador perpétuo" tem se tornado o princípio mesmo de funcionamento do mercado de arte atualmente e ele favorece a especulação a curto prazo. Nessa nova lógica de mercado, o que conta não é o que as coisas serão, mas aquilo que os atores econômicos pensam que elas serão, o que leva ao estabelecimento de uma série de critérios subjetivos que desempenham papel determinante sobre os preços.

Partindo do princípio de que assim como existem "regimes de crença", há também "regimes da paixão", as antropólogas Brigitte Derlon e Monique Jeudy-Ballini (2008: 285), em seu estudo a partir de entrevistas com colecionadores de arte primitiva, demonstram que os valores preconizados no mercado e que
22 Uma das mais antigas sociedades de leilões de arte no mundo, com sede em Londres. 
informam o preço estão mais ligados à subjetividade do colecionador que a características intrínsecas aos objetos. Um objeto autêntico, nas palavras de um colecionador, pode ser definido como um "objeto feito pelos africanos, para os africanos, e utilizado pelos africanos" (Derlon e Jeudy-Ballini, 2008: 49). Logo, o objeto "vivido" é o objeto que terá uma segunda vida na coleção, e, possivelmente, nos museus. Mas, como lembram as autoras, se, por um lado, é necessário pensar que o objeto foi de fato utilizado por indígenas, por outro, o conhecimento das condições precisas desse uso está longe de ser considerado essencial para os colecionadores, e, consequentemente, também para alguns museus e galerias de arte.

Assim, assumindo o aspecto espiritual que há nas coisas veladas, o mercado das "artes primeiras" se alimenta de imagens que não assumem um compromisso com a verdade etnográfica e, ao mesmo tempo em que evocam um passado imaginado, anunciam a sua reinvenção constante no presente. $O$ valor dos objetos de arte primitiva se pauta sobre esse suposto paradoxo do mundo atual ${ }^{23}$.

Em um museu nacional como o quai Branly, as compras iniciais se deram, em geral, buscando completar um conjunto de referências estéticas que, ao mesmo tempo em que eram ditadas pelo mercado e pelo gosto dos colecionadores, também iriam ditar o valor de certos objetos que ganhariam visibilidade nesse mesmo mercado. Um dos papéis que teve o museu, a partir do momento em que foram selecionados os objetos para as exposições inaugurais, foi o de alargar o leque das "artes primeiras", incluindo quatro continentes, o que iria ampliar o interesse europeu, e, particularmente o francês, voltado até então enfaticamente para a arte africana. Para isso, Kerchache e sua equipe iriam contar com um importante apoio financeiro do Estado francês.

Diferentemente da maioria das vendas de arte tribal parisienses habituais, centradas, em geral, na arte africana, a venda Breton, em abril de 2003, tinha o interesse de oferecer os objetos da Melanésia, da Austrália, da Indonésia ou da América do Norte, caros aos surrealistas e raríssimos tanto nas vendas parisienses quanto no mercado em geral. Essa venda, que se tornou famosa pela sua singularidade no contexto francês, tinha ainda o trunfo de ter mantido intacto o célebre atelier do número 42 da rue Fontaine, onde haviam permanecido, por meio século, as obras pertencentes a André Breton. Para além dos pequenos objetos que iriam, por sua vez, pulverizar as estimativas sobre os seus preços, alguns outros mais importantes não tiveram o preço tão elevado, o que permitiu que o quai Branly exercesse o seu direito de preferência sobre diversos lotes, adquirindo, entre outras peças, uma máscara haida em madeira policromada da Colúmbia Britânica, datando do início do século XIX, a 165.116 euros, preço este no limite das estimativas (Wavrin, 2006: 65). A obra mais visada da venda, uma efígie de ancestral uli em madeira policromada da Nova Irlanda, foi comprada
23 Sobre essa noção que permeia as imagens criadas e recriadas no mundo contemporâneo, ver Latour (2002). 
por 1,2 milhões de euros pela filha do colecionador, Aube Breton, e foi oferecida, em seguida, à biblioteca Doucet - preço sensivelmente abaixo dos quase 3 milhões de euros pagos pelo Estado, por uma estátua uli similar, comprada do colecionador parisiense Alain Schoeffel.

Se os agentes do mercado estão em competição financeira pela obtenção de obras as mais raras, incluindo aquelas procuradas pelos grandes museus e que aparecem raramente no mercado de arte, eles se encontram, ao mesmo tempo, em competição intelectual para renovar a oferta por meio da inspeção das zonas de sombras e da reavaliação das obras já conhecidas (Moulin, 2003: 19). Os museus, assim, já não são vistos como entraves para o mercado de arte, uma vez que a colaboração entre os atores culturais e atores econômicos é um dos fatores que contribui para a renovação dos valores num mercado que privilegia a novidade. Certos museus servem em grande medida para fornecer informações úteis sobre o que já se conhece das obras e dos artistas e aquilo que ainda resta conhecer. No caso das "artes primeiras", entretanto, o movimento contrário ocorre com a mesma frequência, de maneira simbiótica. No Musée du quai Branly, ao mesmo tempo em que o próprio museu produz um conhecimento (artístico) sobre as obras em sua coleção ${ }^{24}$, este também recorre ao universo dos colecionadores privados para distinguir entre diferentes tipos de objetos, e para obter informações úteis sobre futuras aquisições.

Um "mundo da arte" se configura, no sentido explicitado por Howard Becker (2010), uma vez que se organizam os diferentes atores que participam do processo de "invenção" e legitimação das "artes primeiras". Se um mundo da arte é composto por todas as pessoas cujas atividades são necessárias para a produção das obras definidas como "de arte" (Becker, 2010: 58-59), logo, no caso das "artes primeiras" o que se tem é um mundo particular formado prioritariamente por conservadores de museus, marchands, colecionadores e alguns etnólogos que aderiram ao projeto artístico. Além disso, esse mundo das "artes primeiras" também é composto por atores imaginados do mundo cultural de onde as obras provêm, que, exceto no caso das artes contemporâneas, não são identificados como "artistas" tendo sido historicamente apagados desse processo de imersão de suas obras em uma outra cultura ${ }^{25}$.

Desse "mundo das artes primeiras" que se constituiu com participação intensa do Musée du quai Branly e de seus principais atores, a partir dos anos 1990, participa também, em certo nível, a antropologia contemporânea. A aproximação da antropologia à história da arte tem início um pouco antes do projeto quai Branly ser idealizado, mas ela está também em sua raiz. Em 1989, a exposição Magiciens de la Terre, organizada por Jean-Hubert Martin, então diretor do Musée d'Art Moderne de Paris, no Centre Ceorges Pompidou e na Crande Halle de la Villette, marcou, pela primeira vez, a vontade de se fazer coexistir em um mesmo es-
24 Por meio das exposições, catálogos, seminários acadêmicos e pesquisas desenvolvidas por acadêmicos selecionados pela instituição de acordo com seus interesses específicos.

25 Sobre esse processo de apagamento dos "artistas" nas "artes primeiras" ver Price (2000). 
paço museal as tradições artísticas ocidentais e não ocidentais. A exposição se apresentou como uma resposta a uma outra, intitulada "Primitivism in the XXth century", e organizada no Museum of Modern Art-MoMA, em Nova lorque, cinco anos antes, que apresentava as artes não ocidentais como fontes cristalizadas para a Arte Moderna (Rubin, 1984 apud Morvan, 2010). Na exposição francesa, as obras de cinquenta artistas ocidentais são reunidas ao lado do mesmo número de obras de tradição não ocidental. $O$ ineditismo do projeto estava no fato de todos os artistas serem apresentados como contemporâneos, e não como primitivos, propondo uma revisão completa da história da arte escrita em um contexto colonial.

A noção de "mágicos" no título da exposição era a única referência ao imaginário europeu tradicional acerca dos povos autóctones. Essa escolha revela que, ainda que a exposição incluísse obras de artistas reconhecidos no Ocidente, ela fora pensada para introduzir as obras ditas não ocidentais no contexto da cultura e da arte do Ocidente. Assim, apesar de um certo primitivismo incontornável presente na noção de "magia" que permeava tal manifestação, a exposição deu início a um movimento de inclusão das artes aborígenes na tradição europeia, e ajudou a promover uma redefinição alargada da arte contemporânea no final do século XX, configurando, consequentemente, um mercado específico voltado para esse gênero de arte híbrida.

Esse mercado, então, por meio de um conjunto definido de convenções criadas por seus atores dominantes, permite a aplicação das suas regras a contextos culturais distintos. Um sistema de convenções se incarna nos equipamentos, nos materiais, nos sujeitos, nas instituições e nos lugares disponíveis. Nessa perspectiva, as obras de arte não representam a produção de autores isolados - e, vale notar, a noção do "autor" como detentor de um "dom" único é uma crença construída no Ocidente e sustentada pelos museus. As obras de arte, pois, constituem a produção comum de todos os atores que cooperam de acordo com as convenções características de um mundo da arte (Becker, 2010: 59). No caso das "artes primeiras", a "obra" é o produto particular de uma tradução cultural por meio da qual elementos de outras culturas são interpretados como arte para poderem circular como mercadorias no contexto internacional. Tudo se passa como se o valor cultural dos objetos em suas culturas "de origem" fosse sacrificado - ainda que não completamente suprimido, visto que a imaginação acerca dessas culturas ela mesma agrega valor aos objetos - em nome de um valor de troca que lhe é agregado na cultura "de destino". Essas categorias são inventadas e reproduzidas pelo mercado que produz e impõe as convenções, de modo que elas são válidas tanto para os objetos etnográficos coletados por europeus quanto para as obras de arte contemporâneas introduzidas no mercado com o aval do "artista". 
“Como 'nós' nos relacionamos com 'eles'?" é a questão fundamental colocada. Ocorre que essas categorias binárias - do "nós" e do "eles", do "Eu" e do "Outro" -, reflexos de antigas oposições entre primitivo e moderno, dominado e dominador, são categorias situacionais e, portanto, instáveis, não podendo ser reproduzidas para definir as estruturas de poder do mundo pós-colonial. Falamos, por isso, em situações de dominação, em que relações de poder podem ser apontadas. O mercado das "artes primeiras" constitui uma dessas situações, em que um sistema pensado para tratar coisas diferentes como se fossem iguais tem a pretensão de ser neutro, quando, na verdade, está incorporado em um contexto desigual mais amplo.

\section{A PASSAGEM DA CULTURA À MERCADORIA}

Ligado a uma demanda de "reparação" das metrópoles em relação às antigas colônias, o mercado das "artes primeiras" se desenvolveu como um instrumento de mediação, estando inicialmente voltado para o gosto de alguns colecionadores que determinavam - ou "inventavam" com base em um regime do gosto específico - o que era "autêntico" como arte indígena e o que não era. Como aponta Molly H. Mullin (1995: 166), a transformação das artes indígenas "em arte, e não em etnologia", no contexto dos Estados Unidos, a partir dos anos 1920 e 1930, se deu como um tipo de afirmação utópica da diferença cultural - uma versão mais colonial do multiculturalismo - que reflete respostas das elites à ascensão do capitalismo de consumo. Ao colocarem o artesanato indígena na categoria de "belas artes", determinados galeristas e colecionadores buscavam tornar a produção artística mais lucrativa economicamente, além de torná-la uma atividade respeitável para os indígenas (Mullin, 1995: 173). Encorajar a produção artística foi, ainda, um meio de evitar divisões agudas entre a economia doméstica e a pública. Assim, para estabelecer a arte indígena como arte e não meramente como trabalho manual ou artesanato, esses galeristas e colecionadores que se pensavam como filantropos reconheciam que seu objetivo devia ser duplo: o de encorajar os indígenas a criarem peças de acordo com o gosto das elites; e o de educar os compradores em potencial.

É claro que um dos modos mais diretos e elementares para os patronos exercitarem a autoridade no mercado da arte indígena era por meio da compra daqueles artigos que mais Ihes agradavam (para eles mesmos e para outros), pagando preços mais altos que a maior parte dos turistas e comerciantes estaria disposta a pagar (Mullin, 1995: 174). Da mesma maneira que os colecionadores que compram uma peça ou expressam aquilo que Ihes agrada a um marchand vociferando o preço que estão dispostos a pagar por um tipo de objeto, esses atores criam o gosto que irá mover o mercado a partir do seu gosto individual. 
Estes podem ser percebidos facilmente como agentes dominantes no mercado das "artes primeiras", simplesmente porque dominam financeiramente as relações comerciais.

A partir da análise de catálogos de vendas de coleções de adornos de plumas da Amazônia (Binoche e Giquello, 2007) similares aos que compõem uma coleção adquirida entre 2010 e 2011 pelo Musée du quai Branly, observamos que os preços dos objetos no mercado, em geral, são mais altos em decorrência de fatores como a forma "espetacular"26 ou as cores utilizadas, que outros como a antiguidade ou os materiais empregados, no caso de objetos desse tipo. Muitos desses fatores são determinados pelo gosto específico de um colecionador ou marchand, e são posteriormente reproduzidos pelos museus se tornando convenções.

Por exemplo, a fragilidade dos materiais pode, em alguns casos, atribuir um valor elevado ao objeto, isto por mostrar que a arte pode ser produzida em condições precárias e sem os recursos disponíveis no Ocidente (isto é, de acordo com o imaginário dos seus compradores). Objetos utilitários, em geral, têm menor valor do que objetos que recebem destaque por seus atributos estéticos. Objetos que têm pigmentos de cores variadas têm preços mais elevados do que objetos de uma cor só, e vendem mais. Objetos singulares são mais procurados pelos colecionadores do que conjuntos de objetos e séries (observou-se, nos catálogos de venda, que muitas séries não eram vendidas). Objetos imponentes como totens, máscaras e esculturas de grande porte têm preços mais elevados e são mais procurados por colecionadores e museus. Objetos que são considerados "representativos" da produção de um grupo social ou de uma região, desde que não deixem de exibir um aspecto "espetacular", são mais procurados que os outros. É nesse sentido que se pode afirmar que a constituição dos valores artísticos se efetua a partir da articulação do campo artístico e do mercado. No campo artístico se operam e se revisam as avaliações estéticas, enquanto que no mercado acontecem as transações e se elaboram os preços. Ainda que esses dois campos tenham, cada um, o seu próprio sistema de fixação de valor, eles estabelecem relações de estreita interdependência (Moulin, 2003: 9). Logo, considerando que o movimento de disseminação da apreciação pelas culturas autóctones nos países mais ricos se deu em um momento chave do desenvolvimento do capitalismo de consumo, não é surpreendente que o discurso sobre a cultura tenha partido de usos mais elitistas do termo, "centrados amplamente nas mercadorias e em suas divisões em arte, artefatos e lixo" (Mullin, 1995: 186). Quem irá determinar essas divisões sobre o patrimônio "dos outros" no Ocidente são aqueles que conciliam o poder de aquisição com um tipo de conhecimento estético sobre as obras (em parte ligado a esse poder de compra).

O fato de o mercado e os marchands terem desempenhado um papel determinante na aquisição de objetos pelo quai Branly se dá também, em grande par-
26 Termo utilizado por colecionadores que passou a ser adotado pelos conservadores do quai Branly para se referir a objetos únicos que atraem a atenção do público (Delpuech, 2011). 
te, pela ausência, no mundo dos museus, de uma expertise independente nesse domínio, o que leva à obrigação de se recorrer à competência dos marchands para avaliar a "qualidade", o valor mercadológico, das peças propostas para aquisição (L'Estoile, 2007: 280). Como consequência dessa nova rede de valores em construção e em ação, ao separar as artes das Américas, África, Ásia e Oceania, o museu ajuda a criar uma nova categoria artística (a das "artes primeiras") e fortalece um mercado em ascensão. O problema, apontado por seus críticos, é que, nesse processo, ele acaba por desumanizar essas "obras", retirando-as de seus contextos e isolando-as em um Ocidente nostálgico.

O processo de transformação de objetos utilitários e, muitas vezes, de uso ritual, em obras de arte, ao alcançar a vitrine dos museus, se passa como a instauração de uma nova forma de veneração - que não exclui as outras formas precedentes, mas que tem sentido primordialmente no contexto do Ocidente moderno. O museu, em constante contato com o mercado, é o agente responsável por reinserir os objetos em uma sacralidade de outra ordem; a sacralidade laica que se dá pela musealização.

Como instituição que se pensa como sagrada não religiosa, o museu não atua como os outros agentes nas aquisições que realiza. A ação do museu é litúrgica, os valores em jogo são secretos, e, em geral, ele não disputa diretamente com os outros atores. Como descrito por Delpuech (2011), o museu, muitas vezes, compra diretamente com os colecionadores privados, e esses trâmites, diferentemente das compras ordinárias, são secretos. Raramente um museu pode revelar quanto pagou por uma peça, ou quais foram os detalhes da transação. No caso da compra recente da coleção de adereços de plumas da Amazônia, realizada por Delpuech para o quai Branly, tratava-se de uma coleção conhecida - que esteve em exposição na Fundação Cartier, em 2000-e de alto valor no mercado de arte (este não revelado pelo conservador). Nesse caso, a compra aconteceu à margem do mercado de arte mais amplo, e em segredo: "No nosso caso, a negociação se deu discretamente e diretamente com o proprietário, sem que outros colecionadores soubessem" (Delpuech, 2011).

O papel do museu diante do mercado é diferente, portanto, daquele dos colecionadores, tanto pelos comprometimentos éticos de uma coleção pública, quanto pela posição política de um museu nacional. Em matéria de antiguidade pré-colombiana, por exemplo, atualmente o Musée du quai Branly se abstém de comprar qualquer objeto por razões éticas e diplomáticas. Apenas doações são recebidas, e apenas se as coleções datam de antes da década de 1970 quando alguns governos locais (como o do México) declararam que o patrimônio arqueológico pertencia aos povos autóctones e a seus territórios ${ }^{27}$. Tal posição, segundo Anne-Christine Taylor (2012), "pode levar a uma realidade trágica, porque restrições dessa natureza não existem entre os colecionadores", e o fato de o museu

27 A lei federal sobre os monumentos e zonas arqueológicas, artísticas e históricas no México data de 1975 (ICOM, 2009). 
não comprar essas peças não impede que pilhagens arqueológicas no México e no Peru aconteçam, provavelmente para alimentar o mercado de arte.

Como se pode perceber, a produção de valor no quai Branly é mediada - por agentes ocidentais, na maioria das vezes - de modo que o mercado, em seus diversos níveis, cria uma distância artificial entre os produtores primários e o museu. A entrada de novos objetos na coleção se dá por meio dessa mediação do mercado, que tem uma gramática própria. O museu, por sua vez, não atua mais como agente de pesquisa no sentido de produzir coleções; como declara Taylor (2012), "não vamos mais até os Kamayurá para coletar os objetos kamayurá". De certa forma, toda uma rede de acesso a esses produtos artísticos dos Kamayurá e de tantos outros grupos e etnias já está constituída para alimentar tanto o mercado quanto os museus. Constatamos, assim, que os mediadores ${ }^{28}$ que levam à produção de "novos" objetos para o mundo da arte se multiplicaram.

Esses mediadores escondem, por exemplo, o fato de que a circulação de objetos de arte indígena produzidos nas antigas colônias se intensifica na medida em que aumenta a sua demanda nas metrópoles ou entre as elites do mesmo país de onde esses objetos têm origem. Nesse sistema comercial, não há dúvida de que aqueles que arrecadam o maior lucro não são os responsáveis primeiros pela produção dos objetos vendidos, mas sim os agentes secundários e terciários que thes agregam valor quando os colocam em circulação no sistema mais amplo. Com efeito, o gosto caro dos ocidentais pelas "artes primeiras" não difere, em parte, do gosto pelos produtos coloniais desenvolvido na época do império colonial. O mercado de arte, logo, tem o efeito de manter e sustentar relações de dominação já estabelecidas no passado.

\section{A ARTIFICAÇÃO DA CULTURA E A MANUTENÇÃo DE UM SISTEMA DE DOMINAÇÃO OCIDENTAL}

Já as primeiras exposições universais que tiveram seções coloniais, a partir de 1862, apresentavam coleções de objetos etnográficos diversos, sobretudo, esculturas africanas. Desde então, nas exposições que se seguiram, todo um gosto pela arte inspirada em produções coloniais iria se desenvolver. A arte colonial iria se tornar um gênero particular em torno do qual seriam fundadas sociedades artísticas e seriam organizados salões anuais com grande visibilidade.

A partir das primeiras sociedades francesas de arte colonial - que disputavam espaço nas grandes exposições - eram criadas, paralelamente, sociedades de artistas das colônias, segundo o modelo da metrópole (Richemond, 2003). Essas sociedades e associações tinham como objetivo disseminar uma arte que era produto das trocas culturais coloniais, e acabavam por servir ao fim comum de absorver a "arte" produzida nas colônias no mainstream artístico da

28 Termo usado no sentido empregado por Bruno Latour (2002). 
época. Por todo o tempo em que o sistema colonial se manteve ativo, o desenvolvimento de uma arte das colônias (como uma ideia híbrida e sem definição precisa) era valorizado tanto nas metrópoles como para além delas. Hoje não se pode dizer que a noção de "arte" não existe nas antigas colônias, ou fora dos sistemas das artes do Ocidente, e, igualmente, não se pode falar em uma "arte indígena" pura, que de fato nunca existiu.

A partir de meados do século XX, deixa-se de falar em "artes coloniais" e pouco a pouco entra em evidência a arte indígena imaginada como "pura" como um tipo de arte primitiva em vias de se legitimar. Esta iria passar a ser exposta nos museus como arte, não como "etnologia". No contexto europeu, um momento determinante na história da arte e da etnologia foi aquele em que se deu o contato de intelectuais como André Breton e Claude Lévi-Strauss com a arte indígena das Américas. O momento em que esses intelectuais franceses haviam emigrado, no contexto da Segunda Guerra Mundial, para Nova lorque, foi quando se iniciou uma vasta circulação de ideias sobre o papel das "artes" atribuídas às populações autóctones das ex-colônias, consideradas até então como objetos etnográficos nos museus, e que passariam a ser denominadas de "arte indígena". Há uma mudança conceitual que se dá no olhar desses intelectuais sobre as obras expostas nos museus.

Ao refletir sobre a exposição de objetos indígenas no American Museum of Natural History, Lévi-Strauss declarava que:

L'époque n'est pas lointaine, sans doute, où les collections provenant de cette partie du monde quitteront les musées ethnographiques pour prendre place, dans les musées des Beaux-Arts, entre l'Egypte ou la Perse antique et le Moyen Age européen. Car cet art n'est pas inégal aux plus grands, et, pendant le siècle et demi qui nous est connu de son histoire, il a témoigné d'une diversité supérieure à la leur et déployé des dons apparemment intarissables de renouvellement (Lévi-Strauss, [1979] 2009: 7). ${ }^{29}$

O que não estava dito, entretanto, na declaração de Lévi-Strauss, era o fato de que, para que essas obras entrassem para os museus de arte, elas teriam que passar por um processo particular de apropriação e transformação, através do qual se distanciariam simbolicamente dos seus produtores, tornando-se mercadorias. O processo que se desenvolveu, de um lado, com os surrealistas, e, de outro, com o pensamento estruturalista de Lévi-Strauss aplicado aos mitos e aos objetos nos museus, seria uma forma de "tradução" e de "acomodação" dessas artes provenientes de outras culturas, em uma cultura hegemônica existente.

O objetivo surrealista - o de, através da arte, deixar o "self" "solto de suas amarras" (Clifford, 2008: 123) - se disseminou junto com os objetos adquiridos
29 "Não está longe, sem dúvida, a época em que as coleções provenientes dessa parte do mundo deixarão os museus etnográficos para tomar o lugar nos museus de Belas Artes, entre o Egito ou a Pérsia antiga e a Idade Média europeia. Porque essa arte não é desigual em relação às maiores, e, durante o século e meio que conhecemos de sua história, ela testemunhou, de sua parte, uma diversidade superior e realizou dádivas aparentemente inesgotáveis de renovação" (tradução nossa). 
por André Breton, Max Ernst e outros, através das instituições em que foram depositados na Europa, o que influenciou, sobretudo no caso da França, a etnologia da época. O exercício antropológico de passar do estranho ao familiar e do familiar ao estranho, nesse caso através dos objetos, implicou, inevitavelmente, a transformação de sujeitos em objetos, para que estes pudessem ser manipulados, vistos e comercializados de acordo com o gosto dominante. A operação de redução, que pode ser percebida como característica do estruturalismo, segundo aponta Alban Bensa (2010: 21), faz com que se perca uma dimensão essencial do social, isto é, a sua historicidade, o fato de que os indivíduos fazem escolhas, em outras palavras, que eles "tecem a sua história navegando entre obrigações e oportunidades".

Nessa perspectiva, o mero vislumbre de um objeto de uma outra cultura em um museu de arte, sobre o qual as únicas informações disponíveis são quanto aos materiais empregados, a região do mundo de onde ele provém, as coleções de que já fez parte e, por fim, o seu número de inventário, não permite, de fato, o reconhecimento da dimensão histórica de uma cultura e de quem a produz. Contrariando o título de uma obra de Lévi-Strauss, o "olhar distanciado" ("regard éloigné"), Bensa (2010: 42) afirma que "o olhar aproximado não é aquele do míope, mas o meio de não ceder às facilidades da generalização". Assim como a "cultura" de um povo não é única e homogênea, os ol hares sobre as culturas devem ser múltiplos de modo que se possa relativizar a própria noção de cultura adotada pela antropologia. Segundo o autor:

Pour qu'il y ait des Français, des Normands, des Hottentots, comme il existe des coqs, des vaches et des ratons laveurs, c'est-à-dire des totalités séparées les unes des autres, il faut que la dimension historique des sociétés soit cantonnée à n'être qu'une 'toile de fond', pour reprendre le terme de Lévi-Strauss. Ce qui est retenu, c'est la synchronie, la répétition, la reconduction, le même. Mais peut-on raisonnablement dire que les Français du XIXe siècle étaient les mêmes que ceux qui vivaient sous Louis XIV, que ceux d'aujourd'hui sont identiques à ceux d'avant 1945, que les colonisés et les colonisateurs ne participent pas pour une part d'une certaine manière du même monde? (Bensa, 2010: 57) ${ }^{30}$

Uma vez perdida (ou deliberadamente esquecida) a história sobre as coisas em seu contexto de origem e as pessoas que as produziram, tem-se que o projeto quai Branly propõe a ressignificação desses objetos para que sejam reintroduzidos em uma cadeia de pertencimentos renovada. Esta, por sua vez, é também uma cadeia de valores, na qual os objetos passam a ser interpretados por uma gramática diferente da que estavam inseridos antes. $O$ ponto que se deve lembrar é que a noção de arte não existiu - antes da colonização, quando muitos
30 "Para que existam os franceses, os normandos, os hotentotes, como existem os galos, as vacas e os guaxinins, isto é, totalidades separadas umas das outras, é necessário que a dimensão histórica das sociedades seja confinada a não ser mais que uma 'tela de fundo', tomando o termo de Lévi-Strauss. Aquilo que é retido é a sincronia, a repetição, a recondução, o mesmo. Mas podemos razoavelmente dizer que os franceses do século XIX eram os mesmos que aqueles que viviam sob Luís XIV, que aqueles de hoje são idênticos aos de antes de 1945, que os colonizados e os colonizadores não participam, em parte, de certa maneira, do mesmo mundo?" (tradução nossa). 
dos objetos foram produzidos - nas sociedades de onde provém a coleção heterogênea do museu. Por isso a enorme dificuldade da classificação. Trata-se, precisamente, do fato de que, no contexto em que esses objetos se constituíram materialmente, divisões radicais, criadas no Ocidente, como as que se impõem entre objeto artístico e objeto utilitário, ou artes e artesanato, ou objeto de museu e mercadoria, não estavam, de fato, colocadas.

Sobre esses objetos inseridos numa rede de ambiguidades, hoje a sua percepção no contexto europeu e o seu consumo nos museus já se baseia num sistema de dominação cultural por meio da disseminação de um gosto dos "outros" (L'Estoile, 2007), que não é, de fato, um objeto recente, mas que já guiava as transações artísticas entre metrópoles e colônias desde a configuração dos primeiros museus de etnografia. As "artes primeiras", inventadas no processo de circulação de objetos etnográficos entre os colecionadores, o mercado e os museus, constituem uma categoria reconhecida de obras de arte que, entre outros aspectos, não estão ligadas a nenhum período particular da história, como se observa na seleção de objetos expostos e adquiridos no Musée du quai Branly. Tal distinção permite que objetos produzidos há muitos séculos e dos quais não se conhece o autor possam entrar para a cadeia museológica como "artes primeiras" tanto quanto aqueles produzidos recentemente por artistas conhecidos. No entanto, é possível considerar que ambos os tipos de objetos são "produzidos" no presente, pois sua produção perpassa uma "invenção" dessas "obras" como "chefs-d'œuvre" no Ocidente atual.

É preciso reconhecer que já se desenvolvem em contextos não europeus "infraestruturas da arte" (Sabella, 2009: 136) por meio das quais o mercado internacional realiza o controle da produção, agrega valor econômico a determinadas obras e promove o reconhecimento, ainda que momentâneo, de certos artistas. Com efeito, atualmente, a maior parte da arte indígena é produzida para um mercado e, em alguns casos ela é produzida por pessoas que foram formadas em escolas de arte, que trabalham com mídias e técnicas do "Ocidente", e que vendem suas obras por meio de marchands em galerias e não em lojas de artesanato. Essa arte indígena, que já é produzida com a intenção de ser arte, logo, se encontra entre pelo menos dois mundos, o que permite que transite entre um e outro.

Preenchendo os diferentes nichos, cada espaço artístico nacional está inserido em um sistema global de trocas culturais e econômicas. A circulação de pessoas, de obras e de informação favorece a interconexão dos mercados. $\mathrm{Na}$ prática isso quer dizer que entre os artistas vindos de fora do mundo ocidental, a maior parte daqueles que têm acesso a esse tipo de carreira internacional foi aceita inicialmente por uma grande galeria norte-americana ou europeia (Moulin, 2003: 78). As redes constituídas parecem, assim, perpetuar bem a hege- 
monia das alianças centrais ${ }^{31}$ e continuar a controlar a elaboração de valores e de reputações. Como resultado, é possível se arriscar em prever uma homogeneização artística mundial sob o controle de um polo dominante, político, econômico e artístico.

A globalização da cena artística, como demonstra Moulin (2003: 78), favoreceu a extensão da oferta e sua renovação, o que é uma exigência permanente do mercado de arte contemporânea e logo também o das "artes primeiras", mas esta é, como aponta a autora, uma renovação controlada. Os atores culturais e econômicos encarregados de descobrir, selecionar e valorizar os artistas e as obras de arte obtêm a sua autoridade através do seu reconhecimento pelo mainstream ocidental, isto é, pela corrente dominante que estabelece, no Ocidente e centrada nele, o que é arte e o que não é. Em outras palavras, os critérios que irão ditar o que é arte contemporânea oriental e o que tem valor no mercado são critérios do Ocidente.

Os museus, neste sentido, têm como objetivo influenciar e, por vezes, renovar o gosto pela arte e estão se ligando cada vez mais aos valores do mercado, alimentando-os tanto quanto se alimentam deles. Idealizado, inicialmente, como um templo de legitimação de uma arte que não tinha ainda a sua instância de consagração, o Musée du quai Branly, atualmente, adquire e expõe arte contemporânea não europeia, e é tanto consumidor como produtor dos valores ligados a essas artes no presente. Entretanto, ao não se definir pela categoria dos museus de arte contemporânea, o quai Branly não assume nenhum compromisso estilístico ou temporal uma vez que expõe uma categoria particular de arte sem história. A coleção do museu é composta de objetos que datam desde a antiguidade mesoamericana até o século XXI, o que apresenta um problema interpretativo que só foi possível de ser resolvido com a adoção de um "estilo" artístico atemporal legitimado e celebrado dentro de um sistema de dominação cultural cujas origens históricas não são difíceis de serem apontadas.
31 Sobre o domínio de países como Inglaterra, Alemanha e Estados Unidos no sistema internacional de arte, ver os dados levantados por Alain Quemin (2013)

\section{ALGUMAS CONSIDERAÇõES SOBRE O PREÇO DA CULTURA E DA ARTE}

Como se buscou demonstrar, os museus são geralmente reconhecidos como instâncias sociais da permanência porque guardam os objetos que circulam na cadeia museológica ao registrarem, reterem e reencenarem os valores que Ihes são atribuídos. Logo, os museus não guardam as coisas meramente, eles guardam e transmitem tudo o que há para além delas; eles se retroalimentam de suas diversas vidas sociais e de cada registro da passagem de um objeto por outros sistemas de valores.

O mercado faz parte dos museus tanto quanto os museus fazem parte do mercado, como se provou nesta breve reflexão sobre um museu francês de arte. 
Assim, a observação dos processos, dos mediadores e dos enunciados, em vez da análise dos objetos e das instituições como estruturas permanentes, permite enxergar a agência dos museus nas outras instâncias sociais, tais como o mercado.

Inúmeros exemplos nos permitem mapear os traços dos museus nos sistemas de troca. A venda recente de uma máscara tapirapé, semelhante a que se encontra em exposição no Musée du quai Branly, revela uma grande elevação do preço desse objeto, cujo valor inicial estimado era de 8 mil euros, mas que foi arrematada em um leilão pelo valor de 72 mil euros. Mas o principal exemplo da agência do museu sobre o mercado está no fato de que, desde a divulgação da escultura chupicuaro como logotipo do quai Branly, ter-se observado um aumento dos preços e da procura por objetos chupicuaro pelos colecionadores e galeristas. Uma escultura similar, da coleção privada Marcel Isy Schwartz, foi vendida em um leilão, em 2010, pelo valor de 85 mil euros (estimada inicialmente em 50 mil euros). Esta provém da coleção de Guy Joussemet, a mesma de onde provém a escultura do quai Branly, e é descrita no catálogo de vendas como "a pequena irmã da Vênus de Chupicuaro do Musée du quai Branly"32.

O critério do preço como elemento considerado para agregar valor a um objeto só é observado na medida em que o conservador baseia as suas decisões nas dinâmicas mesmas do mercado. O museu, então, passa a atender prioritariamente a um regime de valores em ascensão que preconiza a permanência da mudança de interpretações em detrimento do rigor do conhecimento. As culturas se tornam mercadorias caras ao gosto ocidental quando todo um sistema de atribuição de valores está estabelecido para manter o seu consumo acelerado. Assim, o que o museu transmite como "dádiva dos deuses" é, ao mesmo tempo, vendido porque possui valor e vendido para ter valor.

Ao contribuir para a manutenção de um mercado das "artes primeiras" e arbitrar sobre os valores investidos nas obras, o museu é responsável por formular um novo sistema museal pós-moderno, em que a instituição deixa de ser associada aos discursos do passado para estabelecer novas relações presentes com obras que, em sua maioria, tiveram a sua coleta marcada pelo sistema colonial ou foram produzidas por ele. Neste artigo, identificamos alguns dos mediadores humanos entre essas obras e o campo museal francês, buscando, de maneira crítica, entender os mecanismos de produção de objetos indígenas no Ocidente. O museu como o lugar do guardar, reconhecido por produzir mundos simbólicos por meio de sua agência, vem sendo cada vez mais incorporado às estruturas construídas pela economia de consumo em que os objetos, as culturas e as artes não são trocados porque têm valor, mas adquirem valor na medida em que são trocados. O que se almeja trocar, em última instância, não são os objetos em si mesmos, mas os próprios valores constitutivos de uma rede de produção e reprodução de saberes e poderes. É com base na multiplicação dos mediado- 
res entre os atores que produzem, os que vendem e os que consomem certos objetos que se perpetuam, nas sociedades declaradas "ocidentais", tais relações complexas entre os mercados e os museus.

Bruno Brulon é Professor do Departamento de Estudos e Processos Museológicos-DEPM da Universidade Federal do Estado do Rio de Janeiro-UNIRIO, e do Programa de Pós-Graduação em Museologia e Patrimônio-PPG-PMUS (UNIRIO/MAST). Atualmente coordena o Crupo de Pesquisa Museologia Experimental e Imagem - MEI.

\section{REFERÊNCIAS BIBLIOCRÁFICAS}

APPADURAI, Arjun

2007 "Introduction: Commodities and the Politics of Value". In APPADURAI, A. (org.). The Social Life of Things: Commodities in Cultural Perspective. Cambridge, Cambridge University Press, pp.3-63.

BECKER, Howard S.

[1982] 2010 Les Mondes de l'art. Paris, Flammarion.

BENSA, Alban

2010 Après Lévi-Strauss. Pour une anthropologie à taille humaine. Paris, Les éditions Textuel.

BINOCHE, S. e GIQUELLO, R.

2007 Amazonie. $3^{\mathrm{e}}$ Vente. Paris, Collection Marcel Isy-Schwart.

DERLON, Brigitte e JEUDY-BALLINI, Monique

2008 La Passion de l'art primitif. Enquête sur les collectionneurs. Paris, Gallimard.

BRULON, Bruno

2013 "Da artificação do sagrado nos museus: entre o teatro e a sacralidade". Anais do Museu Paulista, São Paulo, v. 21, n. 2: 155-175.

CIARCIA, Gaetano

2001 "Croire aux arts premiers". L'Homme, n.158-159: 339-352. 
CLIFFORD, James

[1998] 2008 "Sobre o surrealismo etnográfico". In CONÇALVES, José Reginaldo S. (org.). A experiência etnográfica: antropologia e literatura no século XX. Rio de Janeiro, UFR], pp.121-162.

1994 "Colecionando arte e cultura". Revista do Patrimônio Histórico e Artístico Nacional, Rio de Janeiro, IPHAN, n.23: 69-89.

DESVALLÉES, André

2007 Quai Branly: un miroir aux alouettes? À propos d'ethnographie et d'arts premiers". Paris, L'Harmattan.

DIAS, Nélia

2007 "Le musée du quai Branly: une généalogie". Le DébatHistoire, politique, société, Paris, Gallimard, n. 147: 65-79.

CODELIER, Maurice

2007 Au Fondement des sociétés humaines. Ce que nous apprend l'anthropologie. Paris, Albin Michel, Idées.

\section{GROGNET, Fabrice}

2009 Le Concept de musée: La Patrimonialisation de la culture des "autres". D'Une rive à l'autre, du Trocadéro a Branly: Histoire de metamorphoses. Paris, tese de doutorado, École des Hautes Études en Sciences Sociales.

HEINICH, Nathalie e SHAPIRO, Roberta

2012 "Postface. Quand y a-t-il artification?". In HEINICH, N. e SHAPIRO, R. (orgs.). De l'artification. Enquêtes sur le passage à l'art. Lassay-les-Châteaux, Éditions de l'École des Hautes Études en Sciences Sociales, pp.267-299.

ICOM-Conseil International des Musées

2009 Liste rouge des biens culturels en péril d'Amérique centrale et du Mexique. Paris, ICOM.

LATOUR, Bruno

2002 "What Is Iconoclash?". In LATOUR, Bruno e WEIBEL, Peter (orgs.). ICONOCLASH: Beyond the Image Wars in Science, Religion and Art. Karlsruhe, Center for Art and Media, pp. 15-40. 
L'ESTOILE, Benoît de

2007 Le Goût des Autres. De l'exposition coloniale aux arts premiers. Paris, Flammarion.

LÉVI-STRAUSS, Claude

[1979] 2009 La Voie des masques. Paris, PLON.

\section{MARTIN, Stéphane}

2007 "Un Musée pas comme les autres". Le Débat-Histoire, politique, société, Gallimard, n. 147: 5-22.

MAUSS, Marcel

[1926] 2002 Manuel d'ethnographie. Paris, Éditions Payot.

MORVAN, Arnaud

2010 Traces en mouvement. Histoire, mémoire et rituel dans l'art kija contemporain du Kimberley Oriental (Nord-Ouest Australie). Paris, tese de doutorado, École des Hautes Études en Sciences Sociales.

MOULIN, Raymonde

2003 Le Marché de l'art. Mondialisation et nouvelles technologies. Paris, Flammarion.

1992 L'Artiste, l'institution et le marché. Paris, Flammarion.

MULLIN, Molly H.

1995 "The Patronage of Difference: Making Indian Art 'Art, Not Ethnology"'. In MARCUS, G. E. e MYERS, F. R. (orgs.). The Traffic in Culture. Refiguring Art and Anthropology. Berkeley/ Los Angeles, University of California Press, pp.166-200.

PRICE, Sally

2000 Arte primitiva em centros civilizados. Rio de Janeiro, UFR].

\section{QUAI BRANLY}

Rapports d'activité, 2003-2011. Disponível em: www.quaibranly.fr, acesso em fevereiro de 2012.

QUEMIN, Alain

2013 Les Stars de l'art contemporain. Notoriété et consécration artistiques dans les arts visuels. Paris, CNRS Éditions, Coll. "Culture et Société". 


\section{RICHEMOND, Stéphane}

2003 Les Salons des artistes coloniaux. Paris, Les Éditions de l'Amateur.

SABELLA, Steve

2009 'Valued in the 'West', Sold in the 'East'. The Need for a Virtual Code of Ethics?". Contemporary Practices Art Journal, vol. V: 136-141.

VIATTE, Germain (org.)

2002 Les Palais des Colonies. Histoire du Musée des Arts d'Afrique et d'Océanie. Paris, Éditions de la Réunion des Musées Nationaux.

WAVRIN, Isabelle

2006 "Une Fulgurante ascension". Beaux Arts magazine, Horssérie, Chefs-d'œuvre du musée du quai Branly, p.60-65.

\section{ENTREVISTAS}

DELPUECH, André

2011 Entrevista em 13 de dezembro de 2011. Musée du quai Branly, Paris.

TAYLOR, Anne-Christine

2012 Entrevista em 18 de janeiro de 2012. Musée du quai Branly, Paris. 


\section{ABSTRACT}

The paper results from the investigation of the museum chain that consecrates the "arts prémiers" in the Musée du quai Branly. As a museum of art, conceived to neutralize the cultural value of objects in their previous contexts before entering the European market, the quai Branly is most exclusively connected to the art market and to collectors in the constitution of their own collection. Such a cultural neutrality, mediated by a process of historical silencing, is produced in a museology of artification in which objects are elevated to the statute of "works of art" in the process that evolves from the museum to the market and vice-versa. In the "arts prémiers", the "work" is a product of a cultural translation by which the elements of other cultures are interpreted as art in order to circulate as commodities in the international context.

Recebido em 16 de fevereiro de 2016. Aceito em 11 de abril de 2017.

\section{KEYWORDS}

Museum, Market, Arts premiers, Artification, Musée du quai Branly. 